\title{
Judicialização e competição em análise subnacional: os casos do Rio Grande do Sul e Ceará
}

\author{
A state-level analysis of judicialization and competition: study of the \\ states of Rio Grande do Sul and Ceará
}

\section{Marcio Camargo Cunha Filho}

\section{Resumo}

O trabalho testa, no plano da política subnacional brasileira, a hipótese de que a judicialização da política está associada à competição política, apresentando abordagem que associa a judicialização a fatores exógenos às instâncias judiciais. Analisam-se dados empíricos referentes à intervenção do Supremo Tribunal Federal (STF) nas políticas estaduais do Rio Grande do Sul (RS) e do Ceará (CE), estados que apresentam elevados e reduzidos níveis de competição, respectivamente. Verificou-se que a judicialização, medida pelo número de intervençóes do STF na política estadual através de Açóes Diretas de Inconstitucionalidade (ADIs), é mais elevada no Rio Grande do Sul. Isso ocorre porque as forças políticas neste estado estão em constante conflito, o que faz com que a competição extrapole o âmbito do Executivo e do Legislativo, estendendo-se em direção ao STF. Já no Ceará, uma pequena elite hegemônica restringe a competição política, inviabilizando a participação de grupos de oposição na política, seja nos tradicionais órgãos representativos, seja na Suprema Corte.

\section{Palavras-chave}

Competição; Judicialização da Política; Ações Diretas de Inconstitucionalidade (ADIs); Política Estadual do Rio Grande do Sul; Política Estadual do Ceará.

\section{Abstract}

This paper tests the hypothesis, in terms of Brazilian subnational politics, that the judicialization of politics is associated with political competition, thus presenting approaches that associate the phenomenon with factors exogenous to judicial courts. The research analyzes empirical data regarding the intervention of the Federal Supreme Court in the state policies of Rio Grande do Sul (RS) and Ceará (CE), federative units that exhibit high and low levels of competition, respectively. Judicialization rates were found to be higher in Rio Grande do Sul. This is because the political forces in the state are in constant conflict, causing competition to move beyond the scope of the Executive and Legislative branches, extending towards the Supreme Court. In Ceará, however, a small hegemonic elite restricts political competition, precluding the participation of opposition groups in politics, whether in traditional representative bodies or in the courts.

\section{Keywords}

Competition; Judicialization of Politics; Direct Actions of Unconstitutionality; State Politics of Rio Grande do Sul; State Politics of Ceará. 


\section{Introdução}

Desde a redemocratização, o Supremo Tribunal Federal (STF) tem participado cada vez mais do processo político brasileiro, provocando crescente interesse no tema. Inserida nesse contexto, esta pesquisa aprofunda um aspecto relevante que não tem figurado entre as principais preocupaçôes dos estudiosos do assunto, contribuindo para a explicação das variaçóes observadas quanto à intervenção do órgão de cúpula do Poder Judiciário brasileiro sobre a política (politics) e sua influência sobre as políticas públicas (policies) em âmbito subnacional.

A hipótese a ser explorada estabelece uma associação positiva entre competição e judicialização política, na qual elevados números de intervençóes do STF por meio de Ações Diretas de Inconstitucionalidade (ADIs) (ação considerada, conforme será explicado, o principal indicador de judicialização) tendem a estar relacionados a níveis igualmente elevados de competição política. Dessa forma, propôs-se uma análise comparativa entre a judicialização de políticas estaduais dos estados do Rio Grande do Sul (RS) e Ceará (CE) frente à Suprema Corte brasileira. Verificou-se que a diferença na intensidade da intervenção do STF em questôes políticas nestes dois estados somente pode ser compreendida tendo-se em vista as relevantes diferenças no contexto sociopolítico destas unidades federativas, visto que que os mecanismos institucionais de que os atores dispóem para ativar o Supremo Tribunal Federal são idênticos em ambos. A correlação existente entre competição e judicialização foi demonstrada pelo fato de que, no RS, estado historicamente marcado pela existência de alto grau de competitividade, a judicialização - traduzida no maior número de suspensão de eficácia de leis ou atos normativos por parte do STF por meio de ADIs - é consideravelmente maior do que no Ceará, onde a hegemonia de elites locais sempre obstaculizou o fortalecimento de grupos de oposição e a formação de um ambiente competitivo.

A pesquisa destaca, portanto, os fatores extrajudiciais que provocam transferência do centro decisório de questôes políticas aos tribunais. Diferentemente, portanto, das abordagens court-centered - que destacam o protagonismo dos juízes no processo de transferência de prerrogativas políticas em favor do Judiciário ${ }^{1}$ - o estudo enfatiza a competição política como fator decisivo para a ocorrência da judicializaçáo. Argumenta-se que a fragmentação política cria o potencial para o conflito entre as

\footnotetext{
${ }^{1}$ Exemplos de abordagens court-centered são a de Epstein e Knight (1998, p. 23), que afirmam que "most judges, in most cases, pursue policy; that is, they want to move the substantive content of law as close as possible to their preferred position" e a de Segal (2008, p. 24), que argumenta que "judges decide cases in light of their sincere ideological values juxtaposed against the factual stimuli presented by the case".
} 
diferentes instituições, forçando assim a intervenção de um terceiro - no caso, o STF - para resolver as disputas políticas.

\section{Competição politica no Rio Grande do Sul e Ceará}

Castro, Anastasia e Nunes (2009) definem competiçáo política como um conceito que engloba essencialmente três fatores: a competição entre governo e oposição, a dimensão ideológica (esquerda e direita) e o grau de dispersão das forças políticas. O gênero competição política se desdobra, para eles, em competição eleitoral e competição legislativa, sendo que a primeira modalidade é aquela verificada durante o período eleitoral, e a segunda, durante o período de governo. As duas formas de competição dão ensejo à criação de dois rankings distintos de competição política, o primeiro levando em conta o índice de competição eleitoral e o segundo, o índice de competição legislativa.

No presente trabalho, apenas o grau de competição legislativa é levado em consideração ${ }^{2}$. Os critérios utilizados por Castro, Anastasia e Nunes (2009) para elaborar os índices de competição legislativa vêm abaixo transcritos:

(a) $\mathrm{Na}$ dimensão governo versus oposição, considerou-se a proporção dos deputados que, em cada um dos estados, posicionou-se como de oposição. Esse indicador resultou de pergunta, incluída no questionário, em que se pedia para o deputado se autoclassificar em uma escala de um (1) a dez (10), em que 1 indicava "máxima aproximação do governo" e 10, "máxima aproximação da oposição". A partir da observação das distribuiçóes de frequência dessa variável em cada um dos estados investigados, decidiu-se considerar como de oposição os deputados que se localizaram nas posições de sete (7) a dez (10) na escala. (b) Na dimensão ideológica, utilizou-se o índice de polarização proposto por Francisco A. Ocaña e Pablo Oñate (apud Díez e Barahona, 2002, p. 348). Tal medida considera a soma das diferenças entre as posiçóes de cada partido na escala direita versus esquerda em relação à média da posição do conjunto de partidos do plenário, elevada ao quadrado e ponderada pelo peso dos partidos na Assembleia. Esse peso, por sua vez, é indicado pelo número de cadeiras que cada um deles obteve nas urnas em 2006. O resultado, para cada uma das Casas Legislativas, foi padronizado de forma a variar

\footnotetext{
${ }^{2}$ Foi descartada a análise da competição eleitoral por acreditar-se que esta possui uma lógica peculiar, que não necessariamente interessa a este trabalho. É que a competição eleitoral levada em conta pelos autores possui uma limitação temporal, sendo medida apenas durante os meses em que a disputa eleitoral está formalmente aberta. $O$ índice de competição legislativa, portanto, possui abrangência significativamente maior, na medida em que leva em consideração a competição travada entre as forças políticas ao longo de todos os quatro anos de legislatura.
} 
de 0 a 1, para que esse indicador contasse, na construção do índice, com o mesmo peso dos outros dois. (c) Com relação à terceira dimensão, a dispersão política, considerou-se o índice de fragmentação parlamentar proposto por Rae e Taylor (1970). A fragmentação parlamentar resulta da relação entre a fracionalização, medida proposta anteriormente por Rae, e a fracionalização máxima, que mede a relação entre o número de cadeiras e o número de partidos parlamentares (CASTRO, ANASTASIA e NUNES, 2009, p. 971).

Adotando estes critérios, os autores chegaram à conclusão de que o Rio Grande do Sul é o estado brasileiro com maior índice de competição legislativa (índice médio de 2,68 em relação aos três critérios acima apontados), ao passo que o Ceará seria o estado de menor competição legislativa (índice médio igual a 0,32 ). Ou seja, a competição legislativa no Rio Grande do Sul seria aproximadamente oito vezes mais intensa do que aquela encontrada na unidade federativa nordestina.

O texto de Castro, Anastasia e Nunes (2009) foi utilizado porque apresenta um indicador claro e objetivo acerca da competição política existente nos dois estados analisados e seus achados não destoam das linhas gerais traçadas por outros autores. Nesse mesmo sentido, Borges (2007), classificando todos os estados brasileiros em termos de competitividade, coloca o Rio Grande do Sul como integrante do grupo "pluralismo competitivo", categoria marcada pela existência de traços de polarização ideológica entre a elite e pela fraqueza relativa de seus governadores. Já o Ceará é classificado pelo autor na categoria "máquina dominante", por vivenciar situação em que um mesmo grupo político detém controle constante e centralizado tanto do Executivo quanto do Legislativo, estendendo o alcance dos controles hierárquico e vertical a outras instituições e processos políticos. É que o estado, desde a redemocratização do país, tem sido dominado por um restrito grupo que, ainda que se denomine como "jovens empresários", se utiliza, segundo Borges (2007), de antigos métodos coronelistas de governança para manter seu suporte político.

Especificamente com relação ao Rio Grande do Sul, Grohmann (2001) afirma que a alta polarização ideológica do estado possibilita uma maior independência dos deputados com relação ao Poder Executivo, visto que eles não precisam necessariamente se alinhar com o governador para obter sucesso em seus projetos políticos e pessoais. Passos (2009) lembra que a política gaúcha é caracterizada por alto nível de alternância no poder, pela formação de governos fortemente polarizados e pela alta fragmentação da Assembleia Legislativa. Por fim, Schneider (2001 apud PASSOS, 2009, p. 10) constata que o sistema partidário do Rio Grande do Sul "has been both fragmented and polarized, generating 
difficulty for elites to form the coalitions necessary to win power and once they have won, making it difficult to make policy".

Por outro lado, é recorrente a constatação de que a política cearense é marcada pela baixa competitividade. Diversos autores têm apontado este estado como exemplo de uma política fortemente hegemônica, historicamente dominada por alguns poucos chefes políticos locais. Nesse sentido, Borges (2008) argumenta que no período que antecedeu a redemocratização do país, o Ceará foi dominado por um acordo oligárquico que permitiu a três grandes chefes políticos do estado manter rígido controle político sobre este, excluindo as demais forças políticas. Tal cenário não parece ter mudado significativamente desde a redemocratização brasileira visto que, entre 1986 e 2010, o Ceará elegeu tăo somente quatro governadores diferentes, de apenas três partidos distintos ${ }^{3}$. Ora, o fato de a chefia do Executivo estadual ter sido exercida, nos últimos vinte e cinco anos, por apenas quatro pessoas e três partidos políticos é, no mínimo, um indício da existência de uma baixa alternância de poder e, consequentemente, da existência de uma política hegemônica dominada por alguns poucos atores políticos relevantes ${ }^{4}$.

Ademais desse fator, o próprio modo de governar dos referidos governadores, apesar de terem sido eleitos durante ou após o processo de redemocratização, reproduz, em muitos aspectos, práticas tradicionalmente patrimonialistas: o primeiro governo, de Tasso Jereissati (1987-1991), por exemplo, foi marcado pela adoção de práticas como a admissão de servidores públicos sem a realização de concursos públicos e a cooptação de lideranças locais através da concessão de subsídios econômicos imediatos para determinados municípios (MACHADO NETO, 2009). $\mathrm{O}$ que se percebe, em resumo, é que há diversos indícios de que a política cearense tem sido marcada, desde a redemocratização, pela dominação, mandonismo, hegemonia e coronelismo, e náo pelo pluralismo e pela competição. Machado Neto (2009) percebe a semelhança entre a forma de atuação dos "novos empresários" cearenses com aquela adotada pelos tradicionais coronéis:

\footnotetext{
${ }^{3}$ Foram governadores eleitos do Ceará: Tasso Jereissati (PSDB), no período 1987-1991; Ciro Gomes (então no PSDB), no período 1991-1994; Tasso Jereissati (PSDB) para as duas seguintes legislaturas, ou seja, 1995-2002; Lúcio Alcântara (PR), no período 2003-2007; e, por fim, Cid Gomes (PSB), atual governador, eleito em 2007 e reeleito em 2010.

${ }^{4}$ Tal indício é agravado pelo fato de que tanto Ciro Gomes (governador entre 1991-1994) quanto Lúcio Alcântara (governador entre 2003 e 2006) governaram o estado com apoio expresso de Tasso Jereissati, que governou o Ceará por três mandatos.
} 
Desse modo, os empresários mantinham relaçóes similares às dos coronéis com o Estado no tocante ao usufruto de recursos públicos para investimento nas respectivas empresas: a fortuna empresarial dos "jovens empresários" foi também dependente dos recursos de financiamento disponibilizados pelo governo, como o Fundo de Investimentos do Nordeste (FINOR), por exemplo. Nesse sentido, os empresários modernos também precisam se relacionar com o Estado e, de certa forma, dependentes dele, tal como os coronéis (MACHADO NETO, 2009, p. 45).

O artigo Pactos na cena politica cearense: passado e presente, de autoria de César Barreira (2008 apud MACHADO NETO, 2009) resume um diagnóstico comum sobre a tradição política desta unidade federativa ${ }^{5}$ :

As fortes marcas oligárquicas dão uma singularidade à política cearense, situando o Estado como um caso paradigmático no contexto das práticas políticas. Os grupos oligárquicos - coronelistas que dominaram a cena política por quase um século -, imprimiram mecanismos ao poder que deram contornos precisos a uma política baseada em relações clientelistas e fortemente calcadas nos princípios de dependência e paternalismo (BARREIRA, 2008 apud MACHADO NETO, 2009, p. 41).

Em face dos distintos contextos políticos de Ceará e Rio Grande do Sul, aquele marcado historicamente pela dominação hegemônica de poucos grupos políticos, e este caracterizado por uma tradição de maior pluralismo e competição, justifica-se uma análise comparativa da judicialização da política estadual nestas duas unidades federativas. Tal comparação é metodologicamente adequada porque, sob o ponto de vista institucional, os atores políticos de Rio Grande do Sul e Ceará dispóem exatamente dos mesmos mecanismos para levar questóes de cunho político à Suprema Corte. Nesse sentido, Snyder (2001) ressalta que a principal vantagem da comparação de unidades subnacionais é justamente o isolamento da variável mecanismos institucionais, pois estes são, neste tipo de comparação, insuficientes para explicar diferenças encontradas com relação aos dados relativos às unidades subnacionais analisadas.

\footnotetext{
5 No ponto, apesar das consideraçóes tecidas até o presente momento, não se pode deixar de mencionar que Machado Neto (2009), respaldado por outros autores, sustenta posição diversa da apresentada neste trabalho. Para ele, a política de dominação dos coronéis no Ceará somente sobrevivia graças à aliança entre o poder político estadual e federal, que foi especialmente forte durante a ditadura militar. A partir da redemocratização brasileira, contudo, o Ceará, ainda na argumentação do autor mencionado, teria passado a contar com maior pluralidade e competição política.
} 


\section{A judicialização da política estadual do Rio Grande do Sul e do Ceará}

\section{Conceitos preliminares}

Para mensurar a judicialização das políticas estaduais do RS e CE, analisaramse todas as Ações Diretas de Inconstitucionalidade ajuizadas perante o Supremo Tribunal Federal entre 5 de outubro de 1988 e 30 de abril de 2012. Ressalta-se que boa parte da literatura especializada utiliza as ADIs para analisar a intensidade da judicialização da política no país. Dentre outros, pode-se citar Arantes (1997, 2004, 2005 e 2006), Arantes e Kerche (1999), Carvalho Neto (2004, 2005 e 2007), Castro (1997), Da Ros (2008a, 2008b e 2008c), Taylor (2006, 2007 e 2008), Oliveira (2008), Taylor e Da Ros (2008), Vianna et al. (1999 e 2007). Isso se justifica porque as $\mathrm{ADI}$ s, especialmente quando há pedidos liminares, viabilizam uma intervenção rápida e direta da Suprema Corte sobre uma política pública, traduzida em lei ou ato normativo infralegal.

Foram analisadas as ações que envolvem, precipuamente, a discussão de uma controvérsia estadual referente aos entes federativos estudados. Incluíram-se, portanto, todas as ações propostas por atores estatais (como os governadores ou mesas das assembleias legislativas dos respectivos estados), bem como aquelas que, independentemente do autor, impugnavam leis ou atos normativos oriundos destes estados. Por outro lado, desconsideraram-se aquelas ações que, embora envolvessem um ator estadual, ou ainda, um ato normativo estadual, tinham como objeto principal a discussão de uma política de âmbito interestadual ou mesmo nacional, deixando de afetar, em caráter principal, a política de um dos mencionados estados ${ }^{6}$. Conforme afirmado, o conceito de judicialização adotado no presente trabalho enfatiza mais os atores políticos relevantes no acionamento do STF do que a postura

\footnotetext{
${ }^{6}$ Nesse sentido, excluiu-se da análise, por exemplo, a ADI 4767, embora esta tenha sido proposta pelo Governador do Rio Grande do Sul. É que, além do chefe do Poder Executivo gaúcho, diversos outros governadores também figuraram no polo ativo da mencionada ação judicial, o que demonstra que o caso tratava, na verdade, de um conflito interestadual, envolvendo governadores de vários estados. Tal fato desconfigura esta ADI como representativa de um conflito eminentemente estadual no Rio Grande do Sul, motivo pelo qual a mesma foi excluída do banco de dados que subsidiou o presente trabalho. No mesmo sentido, foi excluída a ADI 1851, proposta pela Confederação Nacional do Comércio em face de diversos governadores estaduais, dentre eles o do Ceará. É que esta ação impugnava um convênio interestadual firmado por todos os governadores demandados, não envolvendo, portanto, uma disputa diretamente relacionada à política cearense. Em suma, foram incluídas na análise apenas as açóes que envolviam diretamente uma disputa estadual do Rio Grande do Sul ou do Ceará.
} 
dos tribunais em si, pois se parte do pressuposto de que é este acionamento que permite a efetiva intervenção das instâncias estatais ${ }^{7}$.

\section{ADIs contra políticas de CE e RS em números}

A análise inicial do número das ADIs, objeto deste estudo, deixa clara a diferença entre ações que revelam um conflito político no Rio Grande do Sul e as que revelam disputas com relação à política estadual cearense. Enquanto que no primeiro estado foram encontradas 142 ADIs ajuizadas no período de estudo, no segundo este número é de apenas 39. Discriminadas por ano de ajuizamento, as ADIs se distribuem da seguinte forma:

\footnotetext{
${ }^{7}$ No ponto, faz-se necessária uma ressalva metodológica. O levantamento das referidas ADIs foi feito por meio do sítio eletrônico do Supremo Tribunal Federal (<http://www.stf.jus.br>), o qual, infelizmente, nem sempre possui informaçôes completas e atualizadas. Contudo, apesar de eventuais falhas e imprecisões, acredita-se que as informações ali contidas são suficientes para subsidiar uma ampla amostragem do universo que se busca investigar, ainda que possivelmente não possuam todas as açôes que poderiam constar no banco de dados desta pesquisa. Portanto, tais informaçóes serão suficientes para embasar as conclusóes que seguem, embora com as matizaçóes que serão oportunamente ressaltadas.
} 
Gráfico 1 - ADIs envolvendo conflitos estaduais do Rio Grande do Sul e do Ceará, classificadas de acordo com o ano de propositura das referidas açóes ${ }^{8}$

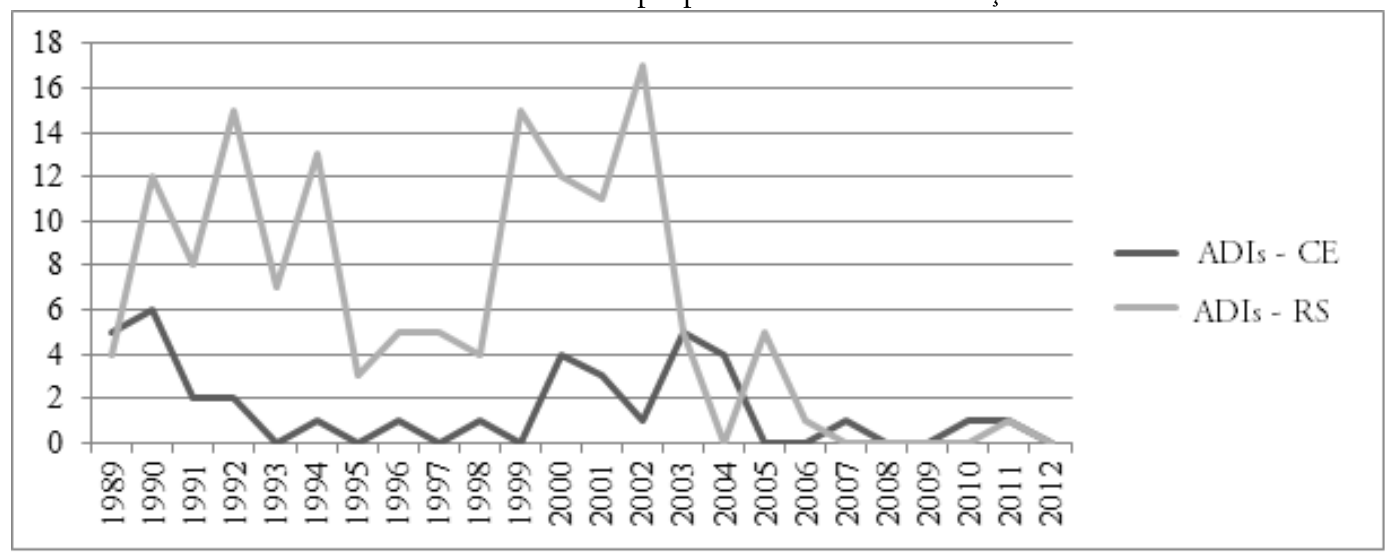

Fonte: Elaboração própria com dados do STF.

Dos dados do Gráfico 1, depreendem-se algumas informações importantes. Em primeiro lugar, fica evidente que a propositura de ADIs apresenta relativa inconstância: em ambos os estados, há anos ou sequência de anos em que muitas açóes são propostas, ao passo que, em outros períodos, nenhuma açáo de inconstitucionalidade é ajuizada. Tal constatação revela que a propositura de ADIs não é um fato corriqueiro ou constante, ou seja, é um fato conjuntural. Tendo em vista, ainda, que a disciplina legal que regulamenta a propositura de ações de inconstitucionalidade pouco mudou no período estudado?, há de se concluir que

${ }^{8}$ Este gráfico revela o que provavelmente é a deficiência mais importante dos dados coletados no presente trabalho: o baixíssimo número de ADIs ajuizadas a partir do ano de 2007 dificilmente significa que estas ações não foram mais propostas nos últimos anos. Antes, este dado revela, muito provavelmente, que açóes ajuizadas a partir desta data simplesmente ainda não foram registradas no sítio eletrônico do Supremo Tribunal Federal. Este fato sem dúvida enfraquece quaisquer conclusóes que levem em consideração o período 2007-2012, porém não invalidam conclusóes aferidas dos dados referentes a períodos anteriores, pois, neste caso, grande parte das ADIs - senão todas - já está disponível no sítio do STF e foram devidamente analisadas no presente trabalho. O que ocorre, na verdade, é que só constam no sítio do STF as açôes já julgadas, o que explica o porquê das açóes mais recentes não constarem, ainda, na base eletrônica do Tribunal.

${ }^{9}$ A única mudança institucional significativa ocorrida durante o período estudado foi a promulgação da lei n. 9.868/98 (BRASIL, 1999), que regulamentou a propositura de açóes diretas de inconstitucionalidade perante o Supremo Tribunal Federal. Ainda que esta lei tenha dificultado, até certo ponto, a concessão de medidas liminares nestas açóes, o fato é que, ao que tudo indica, as mudanças trazidas por este diploma legal não foram capazes de desestimular os atores políticos a fazer uso deste instrumento. Com efeito, o gráfico não demonstra quaisquer indícios de diminuição no 
outros fatores, para além da mera rotina política ou de fatores institucionais, são os responsáveis pelo maior ou menor nível de judicialização da política encontrados nestes estados.

Também é visível o fato de que, no período imediatamente posterior à promulgação das Constituição estaduais de Rio Grande do Sul e Ceará ${ }^{10}$, houve um primeiro pico no ajuizamento de ADIs, em ambos os estados. Tal fato é de fácil compreensão, na medida em que, em um momento importante como o de elaboração das Constituições estaduais, diversos interesses políticos cruciais referentes à organização do Estado, à administração pública, à tributação estadual, entre outros - estariam em jogo, o que constitui fator que tende a acirrar a disputa política, mesmo em ambientes de baixa competitividade. No entanto, já neste primeiro momento, verifica-se uma disparidade entre a mobilização do espaço judicial nestas duas unidades federativas: no Rio Grande do Sul, durante os três anos pós-Constituição de 1988, foram ajuizadas 24 açôes questionando uma política deste estado, ao passo que, no Ceará, foram quinze ações. No total, verifica-se que, no RS, houve 35 ADIs questionando dispositivos da Constituição estadual ${ }^{11}$, ao passo que, no CE, este número cai pela metade (18 ADIS atacaram dispositivos da Constituição estadual $)^{12}$. Esta constatação demonstra que o documento que institui os fundamentos da política estadual foi duas vezes mais judicializado frente ao STF no Rio Grande do Sul do que no Ceará, o que evidencia que o significado normativo do principal ato normativo estadual do RS foi duas vezes mais disputado, na Suprema Corte nacional, do que o conteúdo da Constituição cearense.

Ainda que o foco deste trabalho seja a análise da comparação cross-case entre RS e CE, é relevante também proceder, a título ilustrativo, a uma comparação do tipo within-case, ou seja, uma análise que permita investigar se houve também variação de judicialização ocorrida dentro de cada uma dessas unidades federativas. Esta análise complementar pode também corroborar a hipótese apresentada segundo a qual elevados níveis de judicialização estão associados a altos graus de competição política.

número de ADIS propostas logo após o ano de 1998; pelo contrário, a partir daí o número de açóes envolvendo questóes políticas sul-rio-grandenses aumentou significativamente.

${ }^{10}$ Ambas as Constituiçôes foram promulgadas em 1989.

11 Trata-se das ADIs 134, 146, $1462^{\text {a }}$ MC, 177, 178, 180, 181, 182, 191,192, 255, 330, 396, 409, $473,657,725,775,807,820,821,822,872,892,1001,1027,1060,1414,1521,1630,1824$, 2024, 2481, 2531 e 3022 .

12 Trata-se das ADIs 145, 188, 251, 279, 289, 307, 429, 702, 749, 143-1, 143-2, 1443, 1837, 2212, $2142,3315,3160$ e 3140 . 
Avançando no espectro histórico do Rio Grande do Sul, observa-se uma redução considerável no número de açóes propostas no período 1995-1998, que coincide com o governo liderado por Antônio Britto (PMDB). Para que esta diminuição no número de ações de inconstitucionalidade seja compatível com a hipótese defendida no presente trabalho, há de se esperar que o referido período, na comparação com governos anteriores ou posteriores, seja também marcado por uma diminuição no nível de competição política.

Com efeito, uma análise histórica do governo Britto parece confirmar a hipótese de que o período apresentou menor nível de competição política. Nesse sentido, Carmona (2009) argumenta que o referido governo foi marcado pela formação de uma ampla coalizão, que envolveu formalmente não apenas o partido do chefe do Executivo (PMDB), mas também o PL, o PSDB, o PFL, o PPR e ainda um número significativo de deputados do PTB e do PDT. Dessa forma, o governo Britto acabou por isolar de sua base de sustentação uma única força política relevante no estado, qual seja o PT. A formação desta ampla coalizão de governo assegurou a Britto uma base de apoio parlamentar sólida e ideologicamente coesa, que ultrapassava, em termos numéricos, a maioria absoluta de deputados estaduais. Sobre esse período, ver o diagnóstico de Carmona (2009):

Com a participação de quatro partidos no secretariado (PMDB, PPR, PSDB e PFL) acrescida de nomeaçóes de integrantes do PL e do PTB no segundo e terceiro escalóes, Britto conquistou uma maioria estável na Assembleia. O bloco de apoio formal era constituído por 26 deputados dez do PMDB, 13 do PPR, um do PSDB, um do PFL e um do PL -, ficando a duas cadeiras de conseguir maioria absoluta na Assembleia de 55 deputados. Considerando a sustentação de pelo menos oito deputados do PTB, alcançaria a soma de 34 cadeiras, o que possibilitaria superar os quatro deputados do PPR insatisfeitos com a aliança [...] (CARMONA, 2009, p. 160).

Segundo o autor, o governo Britto logrou distribuir cargos no primeiro e no segundo escalóes de seu gabinete, de forma a integrar as diversas forças políticas do Estado. Tal fato permitiu que seu governo apresentasse razoável grau de estabilidade, sem que muitas forças políticas tivessem motivos para a ele se oporem. Nas palavras de Carmona (2009): 
Tal composição [do primeiro e do segundo escalóes do governo Britto] demonstrou a boa capacidade de articulação do governo Britto junto às diversas lideranças partidárias, oferecendo os espaços estritamente necessários aos partidos para compor um secretariado que lhe garantiu maioria estável na Assembleia Legislativa, unindo rivais históricos dos tempos bipartidários (CARMONA, 2009, p. 163).

Sendo assim, em um ambiente em que as forças políticas se encontravam razoavelmente bem acomodadas, talvez não houvesse motivação para intensificar a disputa política, levando-a para o STF ou para outras instâncias judiciais. Por isso o baixo número de ADIs ajuizadas durante o quadriênio 1995-1998.

Contudo, nem tudo foram rosas durante o período em que Antônio Britto esteve no poder. Com efeito, sua política de privatizaçóes e de contençôes salariais no serviço público, ainda que não gerassem grandes insatisfações para a camada políticopartidária do Estado, certamente causaram descontentamento em parte da sociedade civil sul-rio-grandense. Talvez seja por isso que parte considerável das Ações Diretas de Inconstitucionalidade iniciadas no período (seis de dezessete, ou seja, aproximadamente $35 \%^{13}$ ) foram ajuizadas por representantes da sociedade civil, e não por integrantes da estrutura estatal. Na verdade, o governo Britto foi o período em que o governador do estado menos ajuizou ADIs: foram apenas quatro durante todo o período ${ }^{14}$. Isso coloca em evidência que o chefe do Poder Executivo, no quatriênio referido, simplesmente não precisou estender a luta política em direção ao STF, na medida em que seus interesses já haviam sido satisfeitos em outras instâncias.

O Gráfico 1 ainda é claro ao demonstrar a forte intensificação da propositura de ADIs no período imediatamente subsequente ao governo Britto. Com efeito, durante o governo de Olívio Dutra (1999-2002), ajuizaram-se no total 55 açôes diretas de inconstitucionalidade frente ao Supremo Tribunal Federal. Este número é aproximadamente três vezes maior do que o número de ADIs ajuizadas no governo Britto (em que dezessete açôes foram protocoladas). Teria havido, assim, uma mudança no padrão de competição durante o governo Olívio, a justificar a intensificação da judicialização da política ocorrida no mandato petista?

Novamente, as evidências históricas parecem corroborar a hipótese apresentada neste trabalho. O governo de Olívio Dutra é geralmente classificado como um governo minoritário, durante o qual o chefe do Executivo, em muitas ocasiôes, não tinha força para impor sua agenda ao Poder Legislativo. André Marenco

\footnotetext{
${ }^{13}$ Trata-se das ADIs 1414, 1479, 1574, 1723, 1804 e 1905.

${ }^{14}$ Trata-se das ADIs 1308, 1333, 1504 e 1824.
} 
dos Santos (2012) concorda que o governo Olívio Dutra foi sempre um governo minoritário, marcado pela ausência de formação de qualquer coalizão governamental.

Ainda no sentido de comprovar a dificuldade do governo Olívio em formar uma base sólida de governabilidade, parece relevante o fato de que este Governador, no penúltimo dia de sua gestão (30 dez. 2002), ajuizou, frente ao Supremo Tribunal Federal, nada menos do que quinze Açóes Diretas de Inconstitucionalidade, todas com o objetivo de derrubar leis estaduais ou dispositivos da Constituição Estadual ${ }^{15}$. Sob o ponto de vista político, esta atitude do governador pode ser interpretada como uma última estratégia para tentar realizar os policy goals que ele náo logrou promover durante os seus quatro anos de governo, por falta de apoio político e parlamentar. Se tivesse contado com amplo apoio no órgão legislativo estadual - ou seja, se o nível de conflito entre Executivo e Legislativo não tivesse sido, durante este período, tão acentuado -, muito provavelmente Olívio Dutra não precisaria ter lançado mão desta desesperada estratégia de tentar derrubar, no apagar das luzes de seu governo, nada menos do que quinze atos normativos estaduais.

Já no caso do Ceará, uma possível interpretação do Gráfico 2 é a de que, desconsiderados os anos posteriores a $2006^{16}$, e excetuado o momento imediatamente posterior à promulgaçáo da $\mathrm{CF} / 88$, há um aumento gradual na intensidade da judicialização da política, o que reflete o lento, porém constante, declínio dos tradicionais grupos oligárquicas, em detrimento do fortalecimento progressivo de forças políticas de oposição. O enfraquecimento das oligarquias, notada por Borges (2007), parece vir associada à intensificação, ainda que tímida, da disputa política e, consequentemente, da judicialização.

\section{Temas e proponentes das ADIs}

As figuras abaixo representam, respectivamente, as ADIs do RS e do CE no que se refere ao proponente destas açóes:

\footnotetext{
15 As ADIs ajuizadas nesta data foram as de número 2799, 2800, 2801, 2802, 2803, 2804, 2805 , 2809, 2810, 2811, 2812 e 2813.

${ }^{16}$ Vide nota n. 14.
} 
Gráfico 2 - ADIs relativas à política estadual do RS, classificadas de acordo com o proponente

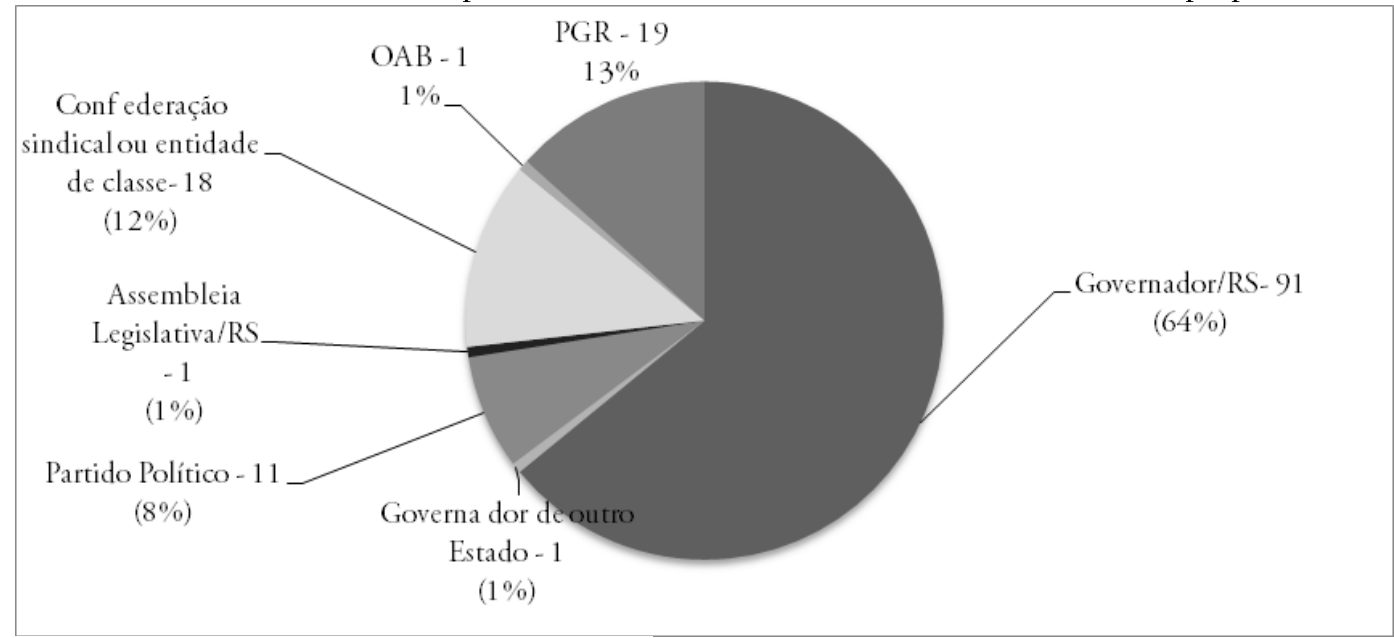

Fonte: Elaboração própria com dados do STF.

Gráfico 3 - ADIs relativas à política estadual do CE, classificadas de acordo com o proponente (direita)

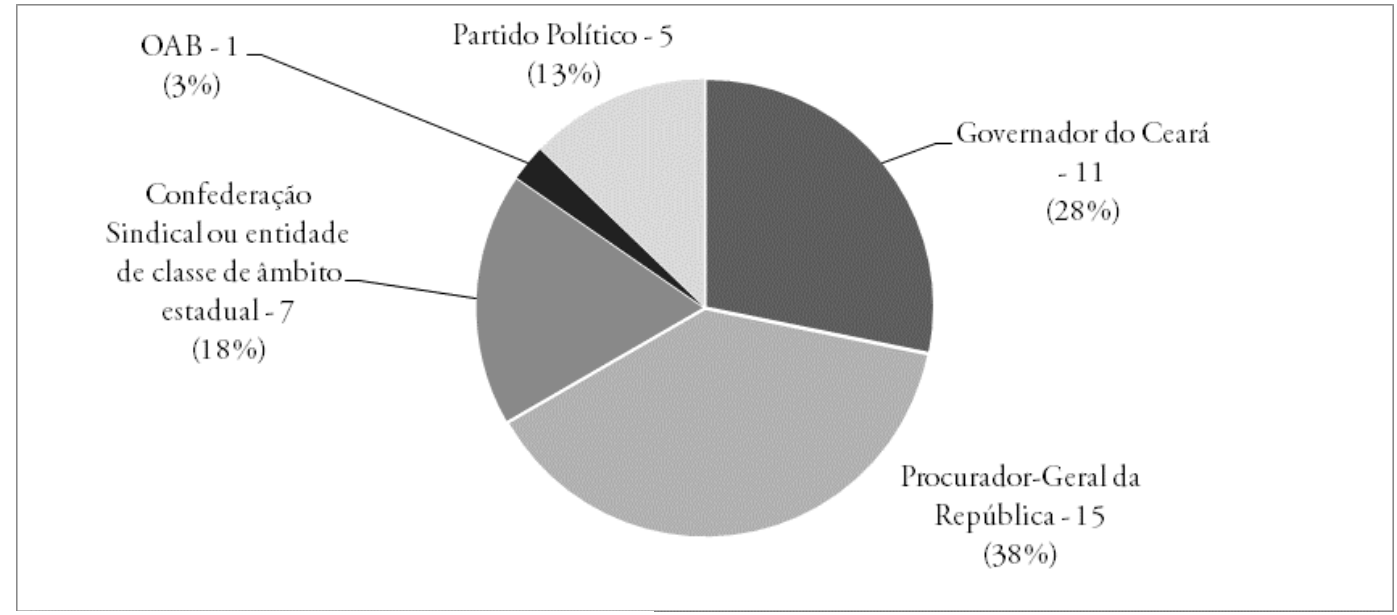

Fonte: Elaboração própria com dados do STF.

Os gráficos acima revelam que a política estadual sul-rio-grandense foi mais judicializada do que a cearense devido, em grande parte, à atuação do governador estadual. No período estudado, o chefe do Executivo gaúcho ajuizou 91 ADIs perante o STF, ao passo que o governador cearense tomou a mesma atitude apenas onze vezes - ou seja, o primeiro ajuizou aproximadamente oito vezes mais açóes do que o segundo, o que representa a mesma proporção da diferença no nível de competição 
política dos dois estados, se adotarmos os critérios do estudo de Castro, Anastasia e Nunes (2009).

Esta constatação vem a reforçar o argumento apresentado anteriormente: a política gaúcha caracteriza-se pelo alto grau de conflitividade e disputa, o que acaba levando os atores a utilizar a judicialização como estratégia para avançar seus interesses políticos. É notório o fato de que o chefe do Executivo gaúcho, mesmo dispondo de ampla gama de prerrogativas institucionais (tais como o poder de veto ou o poder de iniciar legislação em diversas matérias), ainda precise se valer da via judicial para que suas metas políticas sejam alcançadas. Isso demonstra, no mínimo, que a Assembleia Legislativa deste estado tem atuado, em certa medida, como um efetivo contrapeso à força do chefe do Executivo, o que vem a denotar um contexto marcado pelo embate e, consequentemente, pelo pluralismo político. Por outros termos, pode-se dizer que, no RS, a Assembleia Legislativa não é uma mera longa manus do Executivo, como ocorre em ambientes pouco competitivos. Já com relação ao Ceará, o governador, logrando quase sempre fazer valer sua vontade política junto ao Poder Legislativo, simplesmente não precisa ativar o STF com a mesma frequência que o governador sul-rio-grandense. $\mathrm{O}$ contexto cearense caracteriza-se, portanto, não por disputa e pluralidade, mas sim pela formação de grandes alianças políticas que praticamente inviabilizam a formação de uma efetiva oposição que tenha força suficiente para dar eco a uma voz dissonante.

Analisando os dados, percebe-se que, tanto no Rio Grande do Sul quanto no Ceará, a participação da sociedade civil no processo de judicialização da política parece ficar aquém do esperado, ao menos se comparada à participação de outros atores neste processo. Confederações sindicais, entidades de classe de âmbito nacional e partidos políticos, ainda que possuam legitimidade ativa para ingressar com ADIs frente ao Supremo Tribunal Federal, pouco utilizaram este instrumento para impugnar leis estaduais do Rio Grande do Sul ou do Ceará. Possivelmente, estas entidades encontram-se mais preocupadas com a discussão de questóes nacionais, deixando de lado o combate judicial no que diz respeito a matérias estaduais ${ }^{17}$.

Apesar do baixo nível de participação da sociedade civil no processo de judicialização da política de ambos os estados analisados, ainda assim os números

\footnotetext{
${ }^{17}$ A participação de confederaçôes sindicais ou entidades de classe de âmbito nacional no processo de judicialização da política nacional não parece ser tão irrelevante. Vianna et al. (2007, p. 71) chegaram a classificar a sociedade civil como "um dos principais protagonistas no processo de animação da judicialização da política”. Assim, ao que tudo indica, estas agremiaçóes têm sido bastante ativas no que se refere à judicialização de questôes nacionais, relevando a um segundo plano, contudo, a transferência ao STF de questóes políticas estaduais.
} 
referentes ao Rio Grande do Sul são mais expressivos do que os encontrados no Ceará. Note-se que, nos casos de leis estaduais impugnadas por partidos políticos e confederaçôes sindicais, o RS registra aproximadamente o dobro de incidências do que o $\mathrm{CE}$. Isso significa que a sociedade civil não tem empregado, em nenhum dos dois estados, a judicialização como uma estratégia constante e sistemática para avançar suas metas políticas de âmbito estadual, mas no RS ela tem se mostrado mais disposta do que no CE em utilizar esta estratégia.

Outra observação importante é que esta falta de participação da sociedade civil na judicializaçáo de questóes estaduais acaba tendo reflexos no tipo de matéria que é trazida à apreciação do STF. Uma vez que a disputa política é judicializada majoritariamente por atores que integram a estrutura estatal (em especial os governadores estaduais), apenas discussões relacionadas à própria organização do Estado acabam sendo levadas ao Supremo Tribunal Federal. Os Gráficos 4 e 5, que classificam as ADIs de acordo com a matéria principal das leis impugnadas, ilustram este ponto. 
Gráfico 4 - ADIs relativas ao RS, classificadas de acordo com o tema principal da lei ou ato normativo impugnado ${ }^{18}$

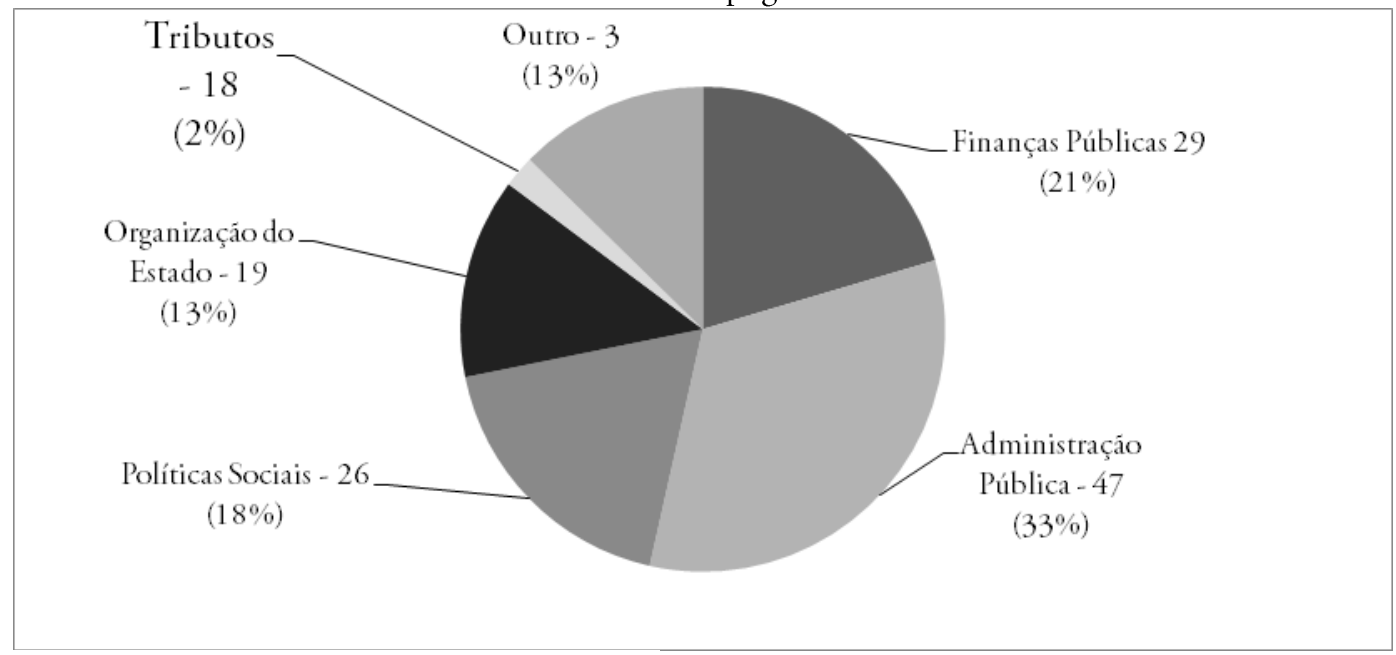

Fonte: Elaboração própria com dados do STF.

${ }^{18}$ A classificação das leis impugnadas dispostas nos gráficos 4 e 5 seguiram os seguintes critérios: Administração Pública: ações que impugnavam diplomas legais relacionados, de maneira direta ou indireta, à Administração Pública em um sentido amplo, englobando as atividades dos três poderes. Foram incluídas ADIs cujo objeto eram leis que: (I) versavam acerca da contratação temporária de servidores públicos; (II) estipulavam requisitos para elaboração de convênios administrativos; (III) dispunham sobre a organização do ensino público; (IV) regulamentavam o regime jurídico de servidor público; dentre outras. Finanças Públicas: açóes que atacavam leis diretamente relacionadas às finanças públicas, como leis orçamentárias, leis que instituíam ou modificavam vencimentos de servidores públicos, ou normas que acarretavam aumento de despesa ou diminuição de receita pública. Tributos: ADIs cujo objeto era precipuamente o ataque a leis que instituíam ou fixavam alíquotas de tributos estaduais, que estabeleciam parcelamento para o pagamento dos mesmos, ou, ainda, os convênios interestaduais que concediam isençóes para o pagamento do Imposto sobre Circulação de Mercadorias e Serviços (ICMS). Políticas sociais: ações que atacavam leis, dispositivos constitucionais ou atos normativos secundários que instituíam ou regulamentavam políticas públicas de caráter social. São exemplos: normas que instituem regulamentação de políticas de trânsito, leis que estabelecem diretrizes de proteção de sítios arqueológicos, leis que disciplinam os serviços de atendimento telefônico, ou leis que regulamentam a produção de alimentos transgênicos. Organização do Estado: as ações que impugnavam regulamentaçóes de questóes intrinsecamente vinculadas à organização e à estruturação do ente federativo, tais como normas que criavam municípios, regulamentavam o processo legislativo estadual, estabeleciam as competências dos Poderes Executivo e Legislativo, instituíam a obrigatoriedade, por parte do governador, de obter autorização legislativa para se ausentar do Estado por mais de quinze dias, dentre outras. 
Gráfico 5-ADIs relativas ao CE, classificadas de acordo com o tema principal da lei ou ato normativo impugnado

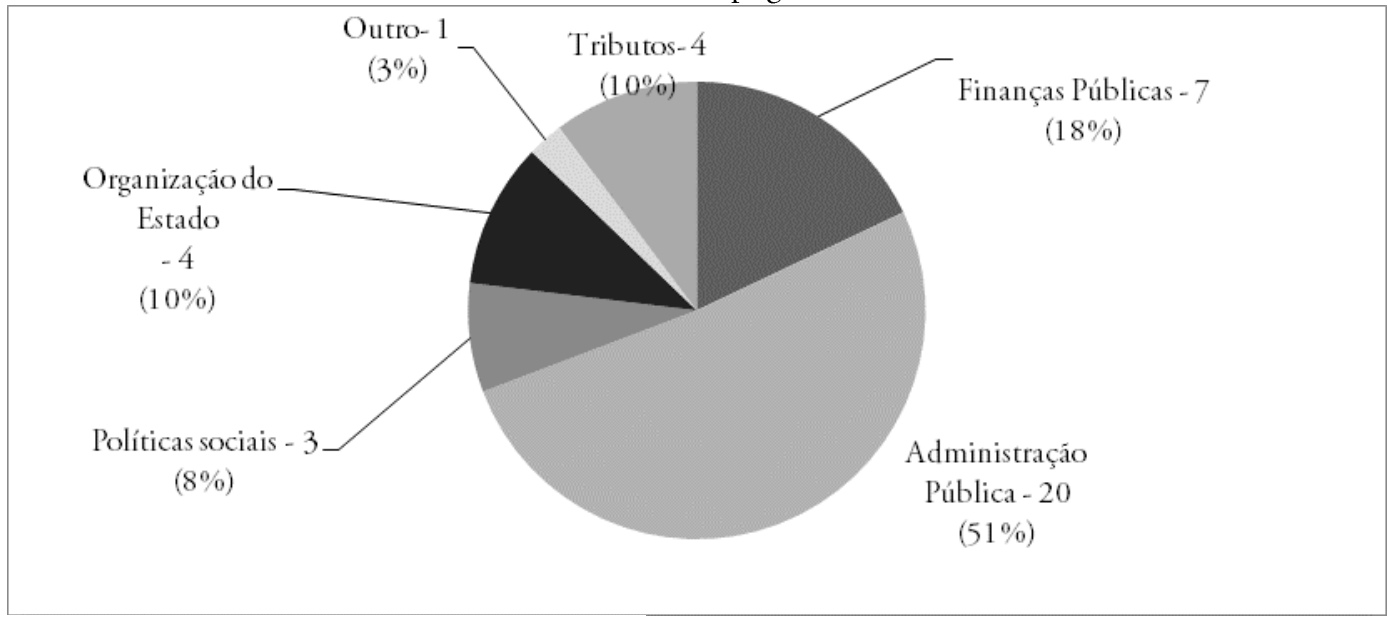

Fonte: Elaboração própria com dados do STF.

Percebe-se que o protagonismo dos governadores no processo de judicialização das políticas estaduais tem uma consequência clara: a grande maioria das questóes levadas ao STF está diretamente relacionada ao funcionamento da atividade estatal, que têm força de afetar principalmente as atividades dos atores políticos, sendo que matérias estaduais mais abrangentes, que poderiam ter consequências para a sociedade civil como um todo, chegam mais escassamente à apreciação da Suprema Corte brasileira.

\section{As decisóes do STF sobre a legislação estadual de RS e CE: a judicializaçáo como resultado da competiçáo dos atores politicos}

Até o presente momento, constatou-se que os atores políticos sul-riograndenses foram mais ativos do que os cearenses no acionamento do STF, ou seja, eles provocaram mais frequentemente a Suprema Corte a participar do processo político estadual.

O resultado disso é claro e compatível com os pressupostos teóricos debatidos na primeira parte deste trabalho: tendo sido chamado a participar mais vezes no processo político gaúcho do que no cearense, o STF efetivamente acabou intervindo mais frequentemente na política do RS do que na política do $\mathrm{CE}$. O que se pretende comprovar neste trabalho é que tal fato não se deu por disparidade de instrumentos processuais à disposição dos atores destes estados. Conforme se ressaltou anteriormente, não há diferença nos instrumentos jurídicos à disposição destes players. Sendo assim, parece evidente a conclusão de que a intensa interferência do 
Supremo na política gaúcha se deu porque os atores políticos sul-rio-grandenses provocaram, por meio de uma mobilizaçáo legal organizada e consistente, esta mais frequente intervenção. Os Gráficos 6 e 7 ilustram a questão:

Gráfico 6 - ADIs relacionadas à política estadual do RS, classificadas de acordo com o resultado do julgamento

\begin{tabular}{|c|c|}
\hline $\begin{array}{c}\text { Extinta sem } \\
\text { julgamento de } \\
\text { mérito/ prejudicada } \\
-19 \\
(13 \%)\end{array}$ & $\begin{array}{c}\text { Aguarda julgamento } \\
\text { Parcialmente } \\
\text { deferida/procedente } \\
-10 \\
(11 \%)\end{array}$ \\
Indeferida/ \\
Improcedente -25 \\
$(18 \%)$
\end{tabular}

Fonte: Elaboração própria com dados do STF. 
Gráfico 7 - ADIs relacionadas à política estadual do CE, classificadas de acordo com o resultado do julgamento $^{19}$

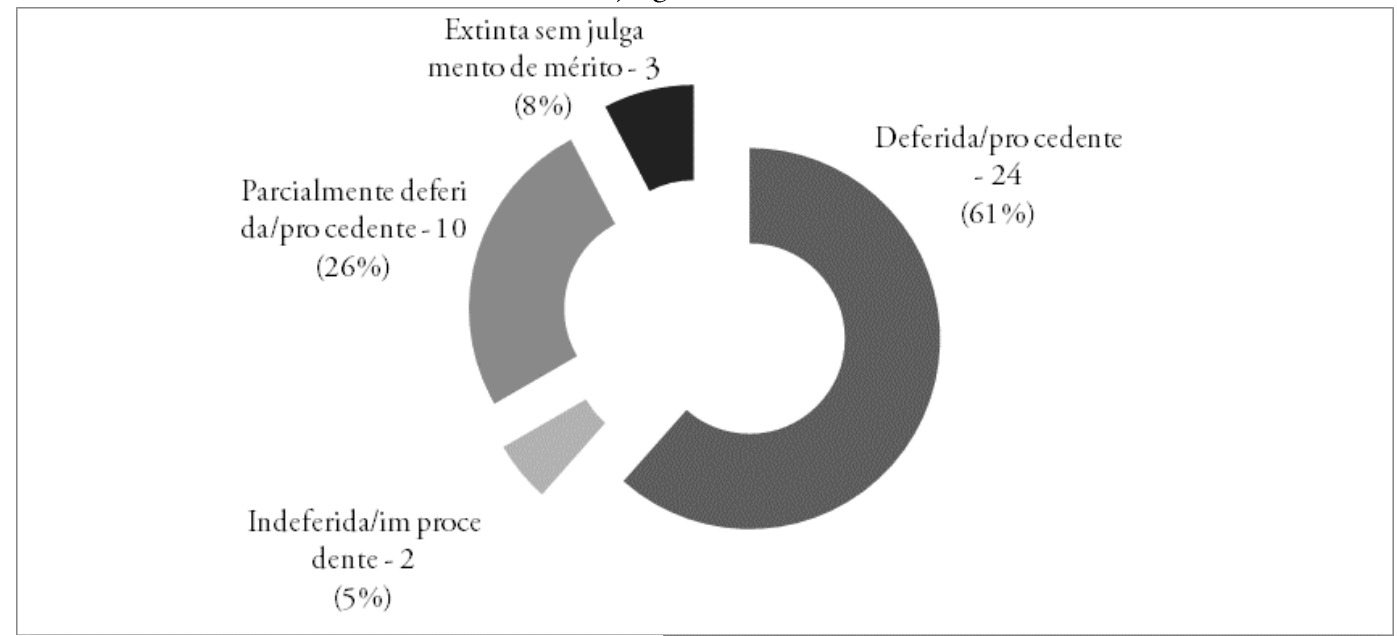

Fonte: Elaboração própria com dados do STF.

Da leitura dos gráficos percebe-se que o STF esteve disposto a interferir na política de ambos os estados: em $87 \%$ das ações que discutiam uma política cearense, a Suprema Corte brasileira invalidou total ou parcialmente o texto legal discutido, enquanto que no caso do Rio Grande do Sul, este percentual, ainda que um pouco menor (em torno de 65\%), continua sendo elevado. Por outros termos, os dados demonstram que o STF está disposto a participar da política de ambos os estados, e possivelmente mais na política cearense do que na sul-rio-grandense ${ }^{20}$. Na prática, contudo, a Suprema Corte interferiu em questôes políticas sul-rio-grandenses em 86 ocasióes (contadas as ADIs que foram integral ou parcialmente deferidas ou julgadas procedentes), ou seja, uma média de aproximadamente quatro intervençóes por ano. No caso do Ceará, contudo, o número total de intervençôes da Corte invalidando total ou parcialmente um ato normativo foi igual a 34 , ou seja, uma média de apenas uma intervenção e meia por ano. O gráfico a seguir sintetiza estas informações.

\footnotetext{
${ }^{19}$ Para a elaboração destes gráficos, levou-se em consideração precipuamente as informações acerca do julgamento liminar das ADIs; somente nas situaçốes em que não foi requerido julgamento liminar é que levou-se em consideração o julgamento de mérito. De qualquer forma, ambas as modalidades foram agrupadas conjuntamente, isto é, se uma ADIN foi liminarmente deferida ou julgada procedente no mérito, foi classificada no primeiro grupo, e se foi liminarmente indeferida ou julgada improcedente no mérito, classificou-se na categoria "indeferida/improcedente".

${ }^{20}$ Vale observar também o STF, segundo Vianna (1997) e Da Ros (2008a), parece estar muito mais disposto a intervir na política estadual do que na federal, nível governamental em que os percentuais de liminares deferidas ou de julgamentos procedentes de mérito são consideravelmente menores.
} 
Gráfico 8-ADIs relativas a discussóes estaduais de RS e CE, classificadas de acordo com o resultado de seu julgamento

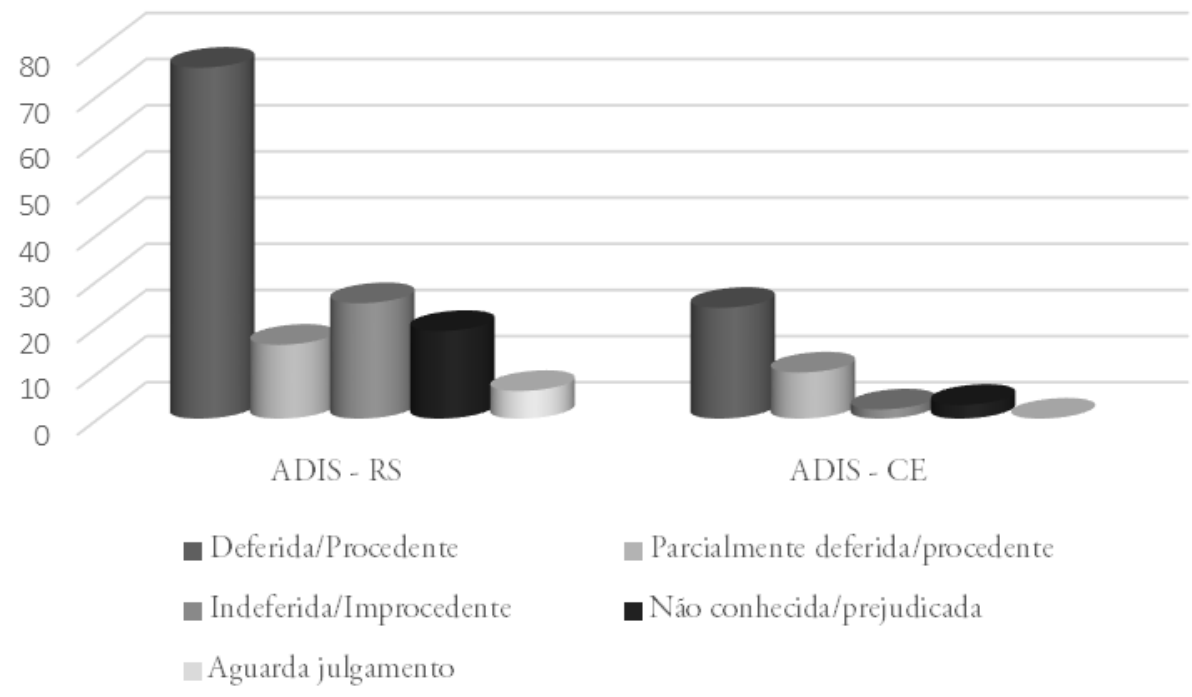

Fonte: Elaboração própria com dados do STF.

Fica evidente a conclusão a que se quer chegar. Ao que tudo indica, a efetiva intervenção das cortes na política de um país ou de um estado está relacionada ao comportamento dos atores políticos daquele local. É que são estes atores que levam questóes políticas aos tribunais e, quando isto é feito com muita frequência e intensidade, forçando a intervenção da Suprema Corte no cenário político por maior número de vezes. A atuação política dos juízes, portanto, está fortemente conectada à quantidade, intensidade e consistência das demandas que os atores fazem desta atuação. Ou seja, ainda que os juízes tenham importância óbvia no processo de judicialização da política, eles nada poderão fazer se não tiverem casos para decidir. Tribunais, como se sabe, são instituiçôes fundamentalmente passivas.

Questôes políticas não chegam aos tribunais por mágica, e para que haja uma efetiva transferência de prerrogativas políticas ao STF, é imprescindível a existência de uma support structure, ou seja, de uma estrutura de suporte da sociedade civil ou de atores políticos que façam com que estas questôes sejam levadas às cortes de maneira consistente e reiterada. A existência desta estratégia de mobilização judicial está diretamente associada à existência de um ambiente de competição política. 


\title{
Conclusões
}

Chavez (2008) resume o porquê da associação entre competição e ativismo judicial. Ainda que sua argumentação esteja mais relacionada à competição econômica, seu raciocínio parece se aplicar igualmente à competição política.

\begin{abstract}
When there is plurality of strong domestic economic actors in competition with one another, they require a secure way to protect property rights, to enforce contracts, and to mediate economic disputes. Competing economic groups that vie for power push for a mechanism of adjudication. In contrast, the concentration of assets stands in the way of the rule of law; there is no need for a body to adjudicate. In countries where a dominant elite is unified, concentrated ownership of the means of production obstructs the emergence of a neutral referee (CHAVEZ, 2008, p. 76).
\end{abstract}

O presente trabalho testou a hipótese de que competição política está relacionada à variável judicialização. Verificou-se que, no Rio Grande do Sul, estado historicamente marcado por possuir grau razoável de competição e pluralismo, houve maior intervenção do STF na política do que no Ceará, local em que a política sempre foi dominada por práticas coronelistas e pela hegemonia de pequenos grupos dominantes. É que em um contexto de competição e oposição entre diversos grupos, espera-se que a disputa política se intensifique e extrapole os tradicionais órgãos representativos, pois os atores forçam a intervenção de um terceiro player imparcial no jogo político. Por outro lado, em um ambiente em que uma pequena elite concentra capital político, econômico e cultural, surge um regime quase hegemônico, em que são reproduzidos os tradicionais métodos de coronelismo e mandonismo, não havendo espaço para que atores oposicionistas tenham voz ativa no cenário político, seja por meio dos tradicionais órgãos representativos, seja por meio da Suprema Corte.

- Marcio Camargo Cunha Filho é Bacharel em Direito e Mestre em Ciência Política, ambos pela Universidade Federal do Rio Grande do Sul. E-mail: marciocunhafilho@yahoo.com.br. 


\section{Referências}

ARANTES, Rogério Bastos. Constitutionalism, the Expansion of Justice and the Judicialization of Politics in Brazil. In: SIEDER, Rachel; SCHJOLDEN, Line; ANGELL, Alan (Orgs). The Judicialization of Politics in Latin America. New York: Palgrave Macmillan, 2005. p. 231-262. - Judiciário: entre a justiça e a política. In: AVELAR, Lúcia; CINTRA, Antônio Octávio (Orgs.). Sistema politico brasileiro: uma introdução. São Paulo: UNESP, 2004. p. 324-235. . Judiciário e política no Brasiı. São Paulo: IDESP/Sumaré/EDUC, 1997.

ARANTES, Rogério Bastos; COUTO, Cláudio Gonçalves. Constituição, governo e democracia. Revista Brasileira de Ciências Sociais, São Paulo, v. 21, n. 61, p. 41-62, jun. 2006.

ARANTES, Rogério Bastos; KERCHE, Fábio. Judiciário e democracia no Brasil. Novos Estudos CEBRAF, São Paulo, n. 54, p. 27-41, jul. 1999.

BORGES, André. Rethinking state politics: the withering of state dominant machines in Brazil. Brazilian political science revieu, Rio de Janeiro, v. 1, n. 2, p. 108-136, set. 2007.

BORGES, André. State government, political competition and education reform: comparative lessons from Brazil. Bulletin of Latin American Research, v. 27, n. 2, p. 235-254, abr. 2008.

BRASIL. Lei n. 9868, de 10 de novembro de 1999. Dispóe sobre o processo e julgamento da ação direta de inconstitucionalidade e da ação declaratória de constitucionalidade perante o Supremo Tribunal Federal. Disponível em: <http://www.planalto.gov.br/ccivil_03/leis/19868.htm>. Acesso em: 12 jul. 2014.

CARMONA, Maurício Espíndola. Articulação política e formação de um governo de coalizão: estudo tópico-teórico da gestão do governo Antônio Britto. Revista Estudos Legislativos, Porto Alegre, v. 3, n. 3, p. 151-184, nov. 2009.

CARVALHO NETO, Ernani Rodrigues de. Revisão judicial e judicialização da política no direito ocidental: aspectos relevantes de sua gênese e desenvolvimento. Revista de Sociologia e Política, Curitiba, n. 28, p. 161-179, jun. 2007.

Revisão abstrata de legislação e a judicialização da politica no Brasil. 2005. 157p. Tese (Doutorado em Ciência Política) - Programa de Pós-Graduação em Ciência Política, Universidade de São Paulo, São Paulo, 2005.

. Em busca da judicialização da política: apontamentos para uma nova abordagem. Revista de Sociologia e Política, Curitiba, n. 23, p. 115-124, nov. 2004.

CASTRO, Marcus Faro de. O Supremo Tribunal Federal e a judicialização da política. Revista Brasileira de Ciências Sociais, São Paulo, v. 12, n. 34, p. 147-156, jun. 1997.

CASTRO, Mônica Mata Machado de; ANASTASIA, Fátima; NUNES, Felipe. Determinantes do comportamento particularista de legisladores estaduais brasileiros. Dados, Rio de Janeiro, v. 52, n. 4, p. 961-1001, 2009.

CHAVEZ, Rebecca Bill. The rule of law and courts in democratizing regimes. In: WHITTINGTON, Keith E.; KELEMEN, R. Daniel; CALDEIRA, Gregory A. The Oxford Handbook of Law and Political Science. New York: Oxford University Press, 2008. p. 63-80.

DA ROS, Luciano. Decretos presidenciais no banco dos réus: análise do controle abstrato de constitucionalidade de medidas provisórias pelo Supremo Tribunal Federal no Brasil (1988-2007). 2008. 213f. Dissertação (Mestrado em Ciência Política) - Programa de Pós-Graduação em Ciência Política, Universidade Federal do Rio Grande do Sul, Porto Alegre, 2008a. 
- Fundamentos sociopolíticos do pioneirismo jurisprudencial e da diversificação do espaço jurídico: notas a partir de estudo de caso. Revista da Ajuris, Porto Alegre, v. 109, p. 217-230, 2008b.

- Poder de decreto e accountability horizontal: dinâmica institucional dos três poderes e medidas provisórias no Brasil pós-1988. Revista de Sociologia e Política, Curitiba, v. 16, n. 31, p. 143-160, 2008c.

EPSTEIN, Lee; KNIGHT, Jack. The choices justices make. Washington DC: CQ Press, 1998.

GROHMANN, Luis Gustavo. O processo legislativo no Rio Grande do Sul: 1995-1998. In: SANTOS, Fabiano (Org.). O Poder Legislativo nos Estados: divergência e convergência. Rio de Janeiro: FGV, 2001.

MACHADO NETO, Francisco Edilberto Menezes. Parlamentares e Poder Executivo: o caso do Ceará. 2009. 112p. Dissertação (Mestrado em Sociologia) - Programa de Pós-Graduação em Sociologia, Universidade Federal do Ceará, Fortaleza, 2009.

MARENCO DOS SANTOS, André. Entrevista concedida ao Jornal Sul21 em 14/01/2011. Disponível em: <http://sul21.com.br/jornal/2011/01/coalizao-e-a-principal-marca-do-governo-tarso-avaliamliderancas-e-cientistas-politicos/>. Acesso em: 12 set. 2012.

OLIVEIRA, Fabiana Luci. Justice, Professionalism and Politics in the Exercise of Judicial Review by Brazil's Supreme Court. Brazilian political science reviєw, São Paulo, v. 2, n. 2, p. 93-116, 2008.

PASSOS, Manoel Caetano de Araújo. Governos de coalizão em unidades subnacionais: os casos do Paraná e Rio Grande do sul, uma discussão preliminar (1990-2002). In: I Seminário Nacional de Sociologia e Política, Curitiba, 2009.

SEGAL, Jeffrey A. Judicial behavior. In: WHITTINGTON, Keith E.; KELEMEN, R. Daniel; CALDEIRA, Gregory A. The Oxford Handbook of Law and Political Science. New York: Oxford University Press, 2008. p. 19-33.

SNYDER, Richard. Scaling down: the subnational comparative method. Studies in Comparative International Development, Providence, EUA, v. 36, n. 1, p. 93-110, Spring 2001.

TAYLOR, Matthew. Judging Policy: courts and policy reform in democratic Brazil. Stanford: Stanford University Press, 2008.

. O Judiciário e as políticas públicas no Brasil. Dados, Rio de Janeiro, v. 50, n. 2, p. 229-257, 2007.

. Veto and voice in the courts: policy implications of institutional design in the Brazilian judiciary. Comparative Politics, New York, v. 38, n. 3, p. 337-355, abr. 2006.

TAYLOR, Mathew; DA ROS, Luciano. Os partidos dentro e fora do poder: a judicializaçáo como resultado contingente da estratégia política. Dados, Rio de Janeiro, v. 51, n. 4, p. 825-864, 2008.

VIANNA, Luis Werneck et al. Dezessete anos de judicialização da política. Tempo Social, São Paulo, v. 19, n. 2, p. 39-85, nov. 2007.

. A judicializaçâo da política e das relaçôes sociais no Brasil. Rio de Janeiro: Revan, 1999. 